\title{
Editorial: Coralline Algae: Globally Distributed Ecosystem Engineers
}

\begin{abstract}
Nadine Schubert ${ }^{1 *}$, Kathryn M. Schoenrock ${ }^{2}$, Julio Aguirre ${ }^{3}$, Nicholas A. Kamenos ${ }^{4}$, João Silva ${ }^{1}$, Paulo A. Horta ${ }^{5}$ and Laurie C. Hofmann ${ }^{6}$

${ }^{1}$ Centre of Marine Sciences, University of Algarve, Faro, Portugal, ${ }^{2}$ Department of Zoology, National University of Ireland Galway, Ryan Institute, Galway, Ireland, ${ }^{3}$ Department of Stratigraphy and Paleontology, University of Granada, Granada, Spain, ${ }^{4}$ School of Geographical and Earth Sciences, University of Glasgow, Glasgow, United Kingdom, ${ }^{5}$ Department of Botany, Federal University of Santa Catarina, Florianópolis, Brazil, ${ }^{6}$ Alfred Wegener Institute Helmholtz Center for Polar and Marine Research, Bremerhaven, Germany
\end{abstract}

Keywords: biodiversity, calcification, climate change, coralline algae, genetic and genotypic diversity, photosynthesis

\section{Editorial on the Research Topic}

\section{Coralline Algae: Globally Distributed Ecosystem Engineers}

From the early days of phycology, coralline algae (CA) have been considered the most formidable and widely distributed algae (Woelkerling, 1988). They compose an abundant and highly diverse group, divided into geniculate (articulated) and non-geniculate species (crusts and rhodolith/maërl forms). CA are present in almost every coastal ecosystem around the world, from the intertidal to mesophotic zones (Johansen et al., 1981; Steneck, 1986; Foster, 2001). They are important ecosystem engineers that provide hard, three-dimensional substrates for a highly diverse fauna and flora (Nelson, 2009), building habitats like the globally distributed rhodolith (or maërl) beds (Foster, 2001), and the large algal bioconstructions that abound in the Mediterranean (coralligenous assemblages, intertidal rims; Ingrosso et al., 2018). In addition, the $\mathrm{CaCO}_{3}$ precipitation within cell walls leads to a high fossilization potential of CA, which are considered the best fossil record among macrobenthic autotrophs since they first appeared in the Lower Cretaceous (Aguirre et al., 2000). It also makes CA major carbonate producers (van der Heijden and Kamenos, 2015), which, considering their abundance and wide distribution, gives them an important role in oceanic carbon cycling and reef building (Adey, 1998; Chisholm, 2003; Martin et al., 2006; Perry et al., 2008) and makes them a group of significant economic interest (Coletti and Frixa, 2017). Like many other marine ecosystems, CA habitats will be negatively affected by future climate change, e.g., due to reduced CA calcification/growth (Martin and Hall-Spencer, 2017; Cornwall et al., 2019) that may eventually lead to ecosystem degradation and reduction of habitat complexity and biodiversity.

Despite the importance of CA and their susceptibility to climate change, the knowledge about these algae is still limited. The nine research articles and one review article in this Research Topic contribute to broadening our understanding of CA across many themes. Genetic variation and reproductive strategy of the European rhodolith species Phymatolithon calcareum was studied by Pardo et al. at large to small scales across 15 sites in the North Atlantic, showing that (i) the rhodolith beds are dominated by tetrasporophytes, potentially due to stability of the habitat, and (ii) that these populations exhibit little sexual recombination (few gametophytes) and low dispersal resulting in high genetic structure. Pardo et al. note that the presence of triploid thalli in Northern regions may further explain the wide distribution of this species in Europe.

In the Gulf of Mexico, rhodolith beds represent a vital macroalgal spore repository that may aid in community recovery after environmental disturbance. In this context, Fredericq et al. describe the endolithic phototrophic diversity of rhodoliths, expanding upon original descriptions 
of endolithic dinoflagellates and haptophytes (Krayesky-Self et al., 2017). The study validates the microscopic identification of algal and fungal cells within rhodolith skeletons and might set to rest the previous debate regarding their cell entry that apparently occurs through tetrasporangial compartments in the sloughing species Sporolithon sinusmexicanum.

Adding to our understanding about the ecological importance of CA, Rindi et al. review CA research in the Mediterranean, beginning with early records and taxonomy, highlighting the importance of these species in geological records and ecosystem functions, and culminating in threats Mediterranean CA face due to climate change. This thorough review identifies knowledge gaps in different fields that should be approached by interdisciplinary research teams spanning the Mediterranean. Regarding the economic importance of CA, Magill et al. experimentally assessed Corallina officinalis turf and species assemblage recovery after canopy removal, finding that higher growth rates and sediment accumulation in harvested turfs facilitate a full community recovery within 4-6 months post-harvest.

Studies on CA combining ecological and physiological aspects are increasingly used to understand the prevalence and dominance of certain CA species in specific habitats, but also to infer about their potential responses to climate change. In this context, Tâmega and Figueiredo examine the role of two tropical crustose CA in early colonization and compare their growth and physiological response to irradiance levels in different reef habitats and sites. While the CA are abundant in mature reef communities, they are not among early colonizers, and the higher growth and productivity rates of Porolithon onkodes under high irradiance in the reef environment seems to be the driving force behind the species' competitive advantage over Lithophyllum stictaeforme. In another study, Sordo et al. assess the effects of seasonal light and temperature variability on the physiology and hence, productivity of the rhodolith Phymatolithon lusitanicum in a temperate rhodolith bed, also showing that this species exhibits a high sensitivity to temperature-related climate change scenarios.

At a different scale, the microsensor study of Hofmann et al. gives new mechanistic insights into a strong biological control of Arctic CA over the calcification process, particularly in the dark, which may be a determining factor for predicting their responses to climate change, i.e., ocean acidification $(\mathrm{OA})$. In this context, there is a growing body of evidence on the sensitivity of adult and early life history stages of CA to OA (Martin and Hall-Spencer, 2017), to which the study of Ordoñez et al. contributes by showing that while OA

\section{REFERENCES}

Adey, W. H. (1998). Coral reefs: algal structured and mediated ecosystems in shallow, turbulent, alkaline waters. J. Phycol. 34, 393-406. doi: 10.1046/j.1529-8817.1998.340393.x

Aguirre, J., Riding, R., and Braga, J. C. (2000). Diversity of coralline red algae: origination and extinction patterns from the conditions potentially enhance photosynthesis and respiration, they also reduce growth of Porolithon onkodes recruits. On the other hand, Johnson et al. report that calcification, but not photosynthetic efficiency of the adult tropical crustose CA Lithophyllum congestum is negatively affected by OA, with more pronounced impacts under fluctuating $\mathrm{pH}$ regimes. Reduced growth of a CA under OA conditions when combined with increased temperature is also demonstrated by Marchini et al. in the articulated intertidal Ellisolandia elongata, a negative effect that is accompanied by shifts from a rich and diverse mobile associated fauna to a more simplified and depauperate community.

In summary, research efforts on CA like those in this special issue should be fostered, as the acceleration of environmental crises related to climate change, widespread coastal pollution, and growing ocean overexploitation represent current and future threats to these organisms and associated ecosystems. Specifically, research should capitalize on increasing our understanding of CA responses to environmental changes and the development of alternative tools to mitigate these impacts.

\section{AUTHOR CONTRIBUTIONS}

The editorial was written by NS and KS and edited by JA, NK, JS, $\mathrm{PH}$, and $\mathrm{LH}$.

\section{FUNDING}

NS was funded by the European Union's Horizon 2020 research and innovation programme under the Marie Sklodowska-Curie grant agreement (No. 844703). KS was funded by the Environmental Protection Agency in Ireland, and the EU Joint Programming Initiative Thematic Annual Programming on Water (2018-W-MS-35). NS and JS received Portuguese national funds from FCT - Foundation for Science and Technology through project UID/Multi/04326/2019. PH was supported by grants from FINEP/Rede CLIMA (01.13.0353-00) and CNPq-Universal (426215/2016-8). LH was funded by the National Science Foundation Ocean Sciences International Postdoctoral Research Fellow program (Grant No. 1521610).

\section{ACKNOWLEDGMENTS}

We thank the contributing authors, reviewers, and the Frontiers in Marine Science Editorial staff for their support in producing this Special Issue.
Early Cretaceous to the Pleistocene. Paleobiology 26, 651-667. doi: 10.1666/0094-8373(2000)026<0651:DOCRAO >2.0.CO;2

Chisholm, J. R. M. (2003). Primary productivity of reef-building crustose coralline algae. Limnol. Oceanogr. 48, 1376-1387. doi: 10.4319/lo.2003.48.4.1376

Coletti, G, Basso, D., and Frixa, A. (2017). "Economic importance of Coralline Carbonates," in Rhodolith/Maërl Beds: A Global Perspective, eds R. Riosmena-Rodríguez, W. Nelson, and J. Aguirre (Basel: Springer International Publishing), 87-104. doi: 10.1007/978-3-319-29315-8_4 
Cornwall, C. E., Diaz-Pulido, G., and Comeau, S. (2019). Impacts of ocean warming on coralline algae: knowledge gaps and key recommendations for future research. Front. Mar. Sci. 6:186. doi: 10.3389/fmars.2019.00186

Foster, M. S. (2001). Rhodoliths: between rocks and soft places. J. Phycol. 37, 659-667. doi: 10.1046/j.1529-8817.2001.00195.x

Ingrosso, G., Abbiati, M., Badalamenti, F., Bavestrello, G., Belmonte, G., Cannas, R., et al. (2018). Mediterranean bioconstructions along the Italian coast. $A d v$. Mar. Biol. 79, 61-136. doi: 10.1016/bs.amb.2018.05.001

Johansen, H. W. (1981). Coralline Algae, a First Synthesis, 1st Edn. Boca Raton, FL: CRC Press, 239.

Krayesky-Self, S., Schmidt, W. E., Phung, D., Henry, C., Sauvage, T., Camacho, O., et al. (2017). Eukaryotic life inhabits rhodolith-forming coralline algae (Hapalidiales, Rhodophyta), remarkable marine benthic microhabitats. Sci. Rep. 7:45850. doi: 10.1038/srep45850

Martin, S., Castets, M.-D., and Clavier, J. (2006). Primary production, respiration and calcification of the temperate free-living coralline alga Lithothamnion corallioides. Aquat. Bot. 85, 121-128. doi: 10.1016/j.aquabot.2006.02.005

Martin, S., and Hall-Spencer, J. M. (2017). "Effects of ocean warming and acidification on rhodolith/maërl beds" in Rhodolith/Maërl Beds: A Global Perspective, eds R. Riosmena-Rodríguez, W. Nelson, and J. Aguirre (Basel: Springer International Publishing), 55-85. doi: 10.1007/978-3-319-29315-8_3

Nelson, W. A. (2009). Calcified macroalgae critical to coastal ecosystems and vulnerable to change: a review. Mar. Freshw. Res. 60, 787-801. doi: $10.1071 /$ MF08335
Perry, C. T., Spencer, T., and Kench, P. S. (2008). Carbonate budgets and reef production states: a geomorphic perspective on the ecological phase-shift concept. Coral Reefs 27, 853-866. doi: 10.1007/s00338-008-0418-z

Steneck, R. S. (1986). The ecology of coralline algal crusts: convergent patterns and adaptive strategies. Annu. Rev. Ecol. Syst. 17, 273-303. doi: 10.1146/annurev.es.17.110186.001421

van der Heijden, L. H., and Kamenos, N. A. (2015). Calculating the global contribution of coralline algae to carbon burial. Biogeosciences 12, 6429-6441. doi: 10.5194/bg-12-6429-2015

Woelkerling, W. J. (1988). The Coralline Red Algae: An Analysis of Genera and Subfamilies of Nongeniculate Corallinaceae. London; Oxford; New York, NY: British Museum (Natural History); Oxford University Press, 268.

Conflict of Interest: The authors declare that the research was conducted in the absence of any commercial or financial relationships that could be construed as a potential conflict of interest.

Copyright (c) 2020 Schubert, Schoenrock, Aguirre, Kamenos, Silva, Horta and Hofmann. This is an open-access article distributed under the terms of the Creative Commons Attribution License (CC BY). The use, distribution or reproduction in other forums is permitted, provided the original author(s) and the copyright owner(s) are credited and that the original publication in this journal is cited, in accordance with accepted academic practice. No use, distribution or reproduction is permitted which does not comply with these terms. 